\title{
Women in Indian Public Administration: Prospects and Challenges
}

\author{
V S Beniwal (Corresponding author) \\ Department of Public Administration, Govt. College for Women, Hisar, India
}

Dr Bulbul Dhar James

Department of Political Science, Jamia Millia Islamia, New Delhi, India

Received: Aug. 12, 2019 Accepted: Sep. 4, 2019 Online published: Sep. 10, 2019

doi:10.5296/jpag.v9i3.10947～URL: https://doi.org/10.5296/jpag.v9i3.10947

\begin{abstract}
To achieve equitable development in society gender equity in civil service is sine qua non. It is crucial that the structures of authority, decision making and implementation should be modified to provide access and equity to all segments of society including women. But ironically, women inhabit only $20 \%$ of decision-making places in public and private realm. Further, worldwide their visibility is merely $1-5 \%$ at apex positions in organisations. Alike, Indian Civil Service (ICS) was manned exclusively by men before 1947. Since Independence, women have been permitted to ender in the public sector including All-India Services. AIS Rules, 1954 entitled the government to demand the resignation of a female officer after marriage on ground of efficiency notwithstanding the Constitutional parity. 1972 gender parity was introduced in the most prestigious services. Nevertheless, the percentage of women in the services is abysmally low. In 2015 women were merely 12 percent and 6.4 percent in Indian Administrative Service (IAS) and Indian Police Service (IPS) respectively. Further, analysis unambiguously exposes that women are confined mainly in the sectors that foster prevailing gender stereotypes of their innateness province of bear, rear and nurture. The proposed study probes gender equity in Indian civil services in general and AIS - IAS and IPS in particular. The study reveals that women are underrepresented in IAS in general and managerial/executive position(s) in particular. Mainly three layers of hurdles are stifling their participation in these services e.g. personal factors, organizational factors and institutional and cultural factors.
\end{abstract}

Keywords: India, women, gender equity, civil service, patriarchy

"There is no chance for the welfare of the world unless the condition of woman is improved. 
It is not possible for a bird to fly on only one wing." (Swami Vivekananda)

\section{Introduction}

Bureaucracy or civil services is the backbone of administration, a vehicle for development and a buffer-system for smooth political transformation in any country. As a matter of fact, civil services work as backbone of the Indian administration. In other words, these services act as central axis around gamut of governance. All the key functions of administration, e.g. policy formulation and implementation, maintenance of law and order and delivery of public goods and services, are performed by these services. Indian civil services are made up of All-India Services and Central Civil Services at union level and the state civil services at province level. Undeniably, the civil services have preformed commendable task since independence. Indeed, these services stirred the nation through every thick and think but well within broad contours and canons chalked out by the constitution.

At present approximately 6.4 million civil servants (Civil Service Survey, 2010) are engaged in the country. Out of which nearly half are working with the union government of India. They are catering needs of more than 1.2 billion people who belongs diverse social, economic, cultural, religious background. In India nearly 5300 civil servants are appointed to serve one million people while this figure is 7100 civil servants per million inhabitants in UK (Cabinet Office, 2008). Pre-independence epoch was only male citadel. Women were hardly visible in public life but exception. The dawn of independence envisaged, devised and executed a more equitable and unbiased social, political and economic arrangements. Consequently, women have begun entering the civil service in all sectors of administration, although they are concentrated mostly in the lower level echelons of administration. According to Fifth Pay Commission (1996), women employees constitute 7.51 percent of the total government employees, but 98 percent of the women employees confined in groups C and D (that is, lower levels) of the official hierarchy.

This chapter analyses women presence in civil service. The chapter is divided into four parts. The first part provides conceptual framework and evolution of civil services in India. The second part examines the visibility of women in All-India Service, that is, IAS and IPS. Women's performance in civil service examination is dissected in the third part. The main challenges faced by women at entry level into the higher civil service are incorporated in fourth part. The final part contains concluding remarks.

\section{Gender}

According to the UNDP (2010) definition of the term, gender refers to the economic, social and cultural attributes and opportunities associated with women and men in a given society. Understanding the differences between women and men, and how they are determined is of key importance in understanding why a gender perspective is so important for development. Sex differences are rooted in biology of males and females and by and large these differences are fixed, universal and innate. On the other hand, the notion of gender is socially constructed, learned and reinforced by the process of socialization across the societies. Gender based differences between men and women are fluid, context-specific and acquired. In other 
words, gender traits are socially determined personal and psychological characteristics associated with being male and female, namely, masculinity and femininity. Garrett emphasized, "gender differences in every society have been created and reproduced through socio-cultural, religious, political and economic factors. He argues that gender-base differences are mostly learnt" (Garett, 1992:8). Apparently without deconstructing gender nuances, the circumstances, issues and problems faced by women in every facets of life cannot be understood as well as remedied entirely.

\section{Gender Equity}

Gender equity is not equivalent to gender equality because the former aspires to achieve equal outcomes for differently located people in social and cultural hierarchy especially men and women while the latter talks about only formal or procedural parity. Alternatively, gender equity necessitates differential treatment towards women to facilitate and engender metamorphic shift in prevailing gender-based power relations. In nutshell, an equity approach calls for re-examination and deconstruction of ubiquitous dominant paradigms, discourse and narratives to mitigate gender-based discrimination and exploitation on both women and men in economic, social and political aspects among others.

\section{Evolution of Civil Service in India}

There is no account of the organisation of the civil service pertaining to the ancient Indian state (200 BC - 1000 AD). However, in the Mauryan period (321-185 BC), Kautilya authored the treatise known as 'Arthashastra' in which he prescribed the attributes of the civil servants for appointment to the court. He framed the rules of business for the civil servants and developed a system of prompt promotions for efficient and effective officials. Finally, he suggested severe punishment for those who were dishonest and indulged in embezzlement. He talked of the responsiveness of the civil servants. To sum up, in antiquity kings, traditional authority ruled the roost, derived legitimacy on the bases of customs and traditions. Fundamentally the civil servants were supposed to offer allegiance and individual commitment towards the rulers.

In medieval times specifically during Mughal rule, Akbar laid the foundation and nourished the system of civil service. He established new revenue-taxation system known as zabt and dahshala. Subsequently it became a major constituent of the Indian taxation system. The civil servants wore a mix hat of welfare and regulatory outlook. Alternatively, in the medieval age, they became state's servants as they were in the state employment.

\subsection{The Higher Civil Service during British Raj}

Modern system of civil services evolved in India after territorial suzerainty of British Crown. Initially these services entrusted the task of revenue collection, and maintenance law and order. Subsequently in 1854 the Macaulay committee recommended that existing patronage system must be replaced by a permanent civil service based on meritocracy. Thus 1855 onwards entry to Imperial Civil Service (ICS) was made on merit. Calculatingly means were devised to restrict Indians from entering in the elite services. Only Britishers who studied at the primer universities such as Oxford and Cambridge were recruited in the services. 
Afterward liberal reforms viz. 1922 onwards organisation of ICS examination in India worked as a catalyst in enhancing visibility of Indian in these privileged

\subsection{The Blueprint of the Civil Service Since Independence}

Our ancestors opted to keep the vestiges of prevailing unified administrative system not only because of its familiarity but also its suitability to maintain unity and integrity of India along with diversity. Explicitly the civil services in India reflect major 'Weberian model' attributes such as academic achievements, career orientation, permanent tenure, remuneration and pension etc. Besides, important posts at Union, State and district levels are exclusively reserved for these services.

The civil services in India can be broadly categorized into three. First the services whose members serve both the centre and the state governments are known as All-India Services (AIS). Secondly, the services whose members work only for union government are termed as Central Civil Services. Finally, states have their own group of services - state civil services. The personnel at the union and the state level are vertically arranged into four groups namely A, B, C, and D group. Group A and B comprise of gazetted officers while group C and D are non-gazetted class. The $\mathrm{C}$ group consists of clerical personnel while group $\mathrm{D}$ comprises of manual/labour personnel.

Interestingly, the Drafting Committee of the Constituent Assembly did not provide a constitutional status to the AIS. However, on the staunch advocacy of First Home Minister of India, Sardar Vallabhbhai Patel, who is also regarded as the Father of All-India Services, the Constituent Assembly included provisions with respect to the All-India Services in supreme law of land. At present there are three AIS. These are - Indian Administrative Service (IAS), Indian Police Service (IPS) and Indian Forest Service (IFoS).

The All-India Services Act of 1951 authorises the Central Government to make rules in consultation with the state governments for the regulation and service conditions of the members of AIS. The member of these services are recruited and trained by the central government but are assigned to different states for work. They serve the central government on deputation and after completing their fixed tenure they go back to their respective states. It must be mentioned here that irrespective of their divisions among different states, each of these AIS form a single service with common rights and status and uniform scales of pay throughout the country. The key objectives of government in creating the AIS are:

- Preserving national unity and integrity and uniform standards of administration

- Neutrality and objectivity - non-political, secular and non-sectarian outlook

- Competence, efficiency and professionalism - at entry by attracting the best and brightest and throughout the career

- Integrity

- Idealism

\section{Women in Indian Public Administration}

According to 2011 census there are 48.5 percent of females out of total population of 1.2 
billion. But women make up merely 25.5 percent of the workforce in India. They occupy merely 20 percent positions in public sector. Dismally their presence is less than 15 percent of senior civil service posts in the government of India. Further, they are head/secretary of just 15 departments/organisations out of total 95.

\subsection{Representation of Women in the Civil Services of India}

Women's entry into civil service is a more recent phenomenon in most countries. The Indian Civil Service was a male service. Indian Civil Service (ICS) was manned exclusively by men before 1947. Since Independence, the Constitution has permitted Indian women to enter the administrative services, especially in the public sector. Women entered the educational, medical, and postal and telegraph services and were mostly concentrated in lower levels of the official hierarchy (Maheshwari 2006:69).

After independence the Constitution of Indian grants right to equality of opportunities to all citizens. Thus, the law of land flushes out discrimination and paves way for the fairer sex to enter in the coveted service. In other words, the Constitution of India ensures quality of opportunity in matters of public employment. Explicitly, therefore, gender discrimination is illegal and, strictly prohibited in every walk of life. However, rule 5 (3) of the Indian Administrative Services' Rules of 1954 empowered the government to demand the resignation of a female officer after marriage on ground of efficiency. After women parliamentarians and women leaders raised a hue and cry against this provision, the services rules scrapped from the rules book in 1972.

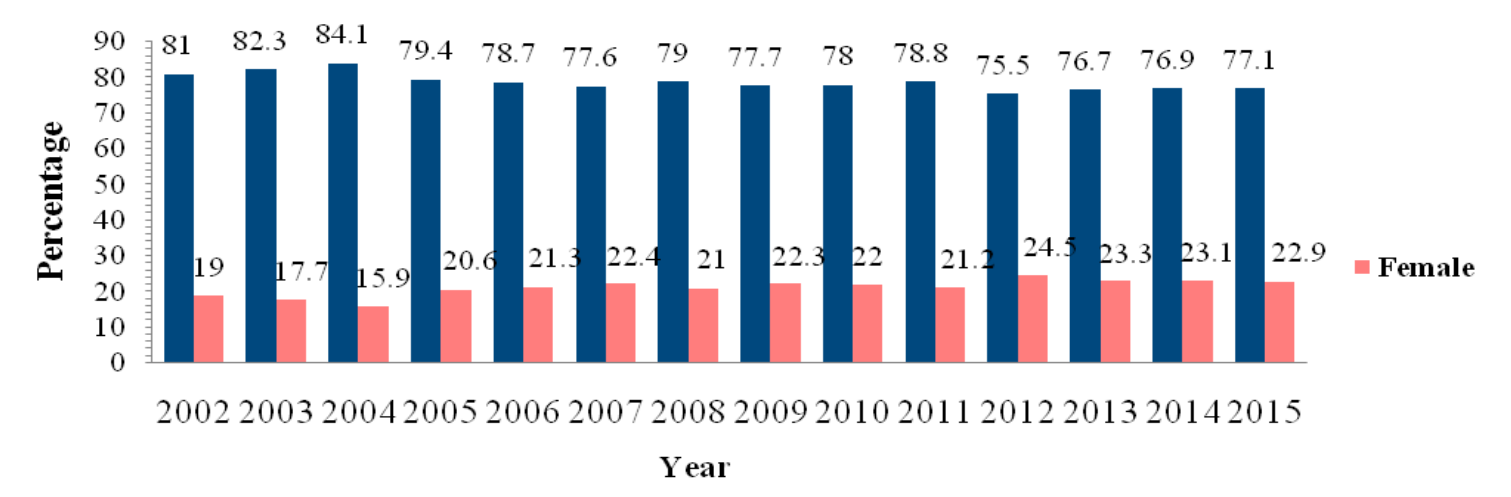

Figure I. Percentage of Women in the Civil Service (Direct Recruitment)

Presently, the percentage of women civil servants are barely in two digits at entry level, Therefore, their visibility in public services is abysmally low. The figure I depicts that women's strength is hovering around one fifth of the total membership of CS.

The figure II below, demonstrates that women constitute merely 7.5 percent of the total strength of All-India Services. Their attendance is highest in IAS cadre while they registered lowest presence in IFoS. The India Police Service also is a masculine enterprise as women are hardly visible. Alternatively, women make up only 5.6 percent of total strength of IPS .The representation of women is just 10 percent civil services as a whole. The proportion of women is highest in the case of Indian Postal Service (23\%) followed by Indian Account \&Audit Service $(18.3 \%)$. On the other hand, their representation is relatively lower in IPS 
(5.6\%), IFoS among others.

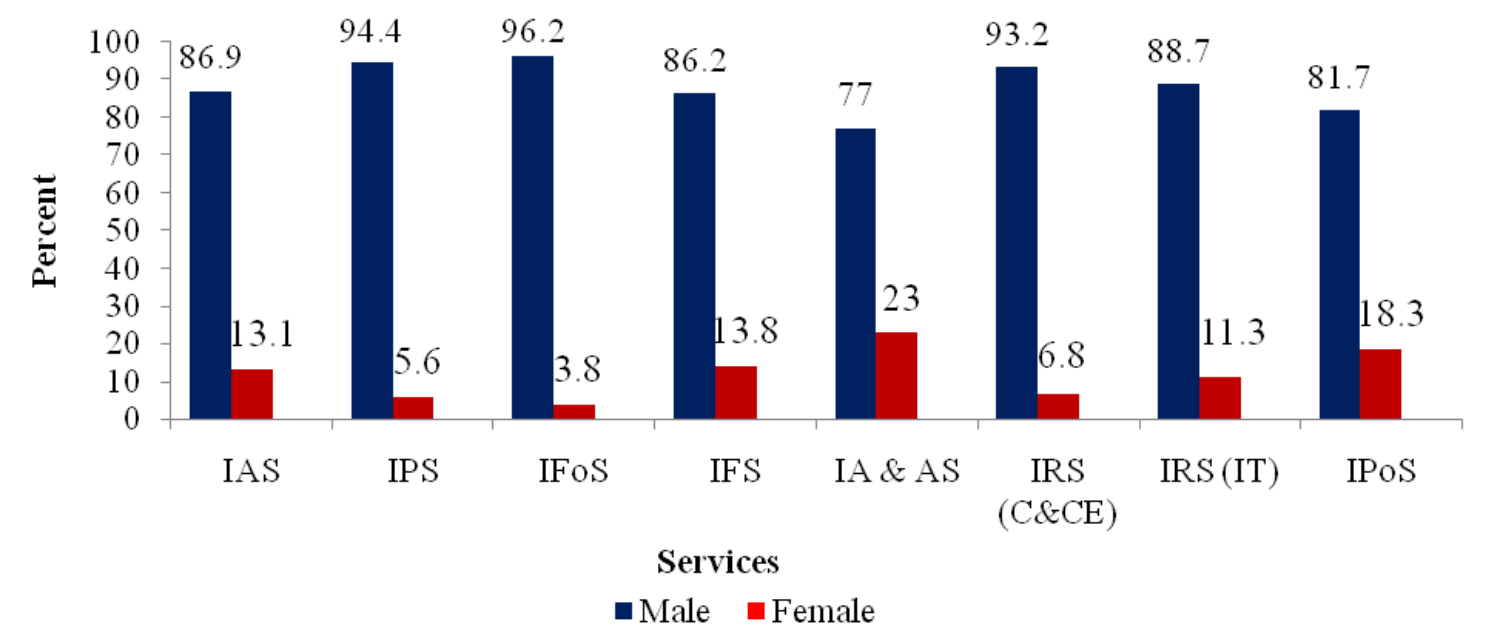

Figure II. Male-Female Ratio in Civil Services Cadre-wise in 2015

5.1.1 Women in the India Administrative Services at Higher Administrative Grade (HAG)

1972 formal gender parity at best has flushed out de jure gender discrimination in AIS successfully. But de facto gender discrimination in the workplace remains all too prevalent. The percentage of femocrats (Femocrat is used for a female senior civil servant/bureaucrat. The term is invented in Australia in 1970s ) remains very low-not more than 15 percent of the total especially in office of substance i.e. HGA.

The glimpse of the table II provided below plainly demonstrates that the apex level and HGA of IAS are 'male only club'. The political bosses have a penchant disposition of replicate their gendered cognition while appointing their support staff. For instance, one can see that two of the most powerful executive arms, that is, the PMO and the Cabinet Secretariat are fully androgenic because when it comes to the question of chairing vital portfolios/departments these are extremely male-dominated organisations. There are only 15 women secretary in various ministries at union level. Further analysis unambiguously exposes that women are confined mainly in the sectors/departments that foster prevailing gender stereotypes of their innateness province of bear, rear and nurture.

Table II. Women in Permanent Executive as on 01.08.2016

\begin{tabular}{clcccc}
\hline SN & \multicolumn{1}{c}{ Designation } & Total & Man & Women & Women \% \\
\hline $\mathbf{1}$ & Secretary in President/VP Office & 02 & 01 & 01 & 50 \\
$\mathbf{2}$ & Secretary in PMO & 03 & 03 & Nil & Nil \\
$\mathbf{3}$ & Cabinet Secretariat & 05 & 05 & Nil & Nil \\
$\mathbf{4}$ & Secretary in Union Ministries & 85 & 71 & 14 & 16.4 \\
& $\quad$ Total & 95 & 80 & 15 & 15.7 \\
$\mathbf{5}$ & Chief Secretary in States/UTs & 36 & 34 & 02 & 5.5 \\
\hline
\end{tabular}

(Source: DoPT, Ministry of Personnel, Public Grievances and Pensions, GOI)

While male officers can catch up with superiors and others who matter outside office as well, 
it is just home-after-office for women. And the brutal reality is that this acts against them as they are tagged 'undependable'. Currently, a number of influential women secretaries are at the helms of various departments, but 'key and hard' portfolios like home, defence and finance do not have any women secretary. The factors that work at securing the cabinet secretary post and other coveted ministries are age, high ranking in merit-cum seniority list and at times prior experiences in ministries in addition to luck and influence. For example, we can envisage unfair game from unceremoniously departure of the foreign secretary, Ms Sujatha, Singh in January 2015. It has, further, been observed that women in higher level administrative positions tend to be less receptive to the voice of women's movements.

\subsection{Women in the Indian Police Services}

Kerala was the first Indian state to have women in the police force, beginning with the first woman inducted into the then Travancore Royal Police in 1933. Thereafter recruitment of women into the police in other states began only after independence, and even then it was sporadic at best. It was not until 1972 that the first woman was appointed to the Indian Police Service. By the time the National Police Commission completed its eight reports in 1981, women accounted for a mere 3000 or $0.4 \%$ of the total police in the country.

As on $1 / 1 / 2015$, there are 110872 female police personnel in India, making up a national average of $6.4 \%$ of the police. Many states have acted on the Ministry of Home Affairs' advisories to adopt a reservation (33\%) policy for women in police forces at entry level. However, the target remains very much on paper and the government is least interested to address the issue. Maharashtra has had a reservation (30\%) in place since 1971 (the longest running at 44 years to the present), but women police are barely pushing $10.9 \%$ of the force. Even with evidence of minor incremental gains, these dismal figures reveal the lack of priority to actually fill the numbers with women in police departments.

Table II. Women in Police as on 01.01.2015

\begin{tabular}{|c|c|c|c|}
\hline Rank & Total & Woman & Percentage of Women \\
\hline Director General of Police (DGP) & 29 & 01 & 3.4 \\
\hline Special DG/Additional DG & 441 & 24 & 5.4 \\
\hline Apex Level & 470 & 25 & 5.3 \\
\hline Inspector General of Police (IGP) & 547 & 46 & 8.4 \\
\hline Deputy Inspector General (DIG) & 410 & 23 & 5.6 \\
\hline Senior Level & 957 & 69 & 7.2 \\
\hline Senior SP/ Commandant & 2497 & 192 & 7.6 \\
\hline $\begin{array}{l}\text { Additional Superintendent of Police } \\
\text { (ASP)/Deputy Commandant }\end{array}$ & 1978 & 187 & 9.4 \\
\hline Junior level & 4475 & 379 & 8.4 \\
\hline Total & 5902 & 473 & 8.0 \\
\hline
\end{tabular}

(Source: Annual Report 2015, BPRD)

Woman as the head of the department of police in states is a rarity. There are only few and countable instances when a woman occupied the position of the Director General of Police 
(DGP). Alternatively, invariably the apex of IPS is 'male only club'. The table II reveals that women constitute merely 5.3 percent of the total strength of DGP/Spl. DG/ADGP posts in Indian Police Service. Further, at senior level (middle stratum) their situation is slightly better, that is, women are 7.2 percent of the total membership of the service. Finally, their condition is marginally improved at the junior level. In other words, women are 8.4 percent of the total figure at junior level. Apparently, the data expound that the phenomenon of 'glass ceiling' is being experienced by women in the service. Male model of police; non-acceptability of women by their male counterparts; irregular working hours, hierarchic pressure and dealing with anti-social element; and uncertain role in department (women are placed in domestic and family matters) which limit them to 'traditional roles' among other are major challenges faced by women in police.

\section{Findings and Discussion on Women Performance in Civil Service Examination}

The CSE is deemed to be of one of the most difficult examination in India. It is conducted in three successive stages: preliminary Examination, main Examination and personality test or interview. The performance of women in CSE is analyzed in the following text.

\subsection{Women's Performance in Civil Service (Preliminary) Examination}

The Civil Services Examination (Preliminary) is one of the toughest examinations. While lakhs of candidates take this examination and only thousand odd qualify it. For instance, nearly 3.2 lakh candidates appeared for CSE(P) in 2013. Only 14959 candidates had appeared in the Civil Services Examination (Main), 2013. In other words, merely ten thousands plus make it to the next stage, that is, main examination. It is evident from the figure III that male candidates have performed far better than the female candidates in CSE(P).

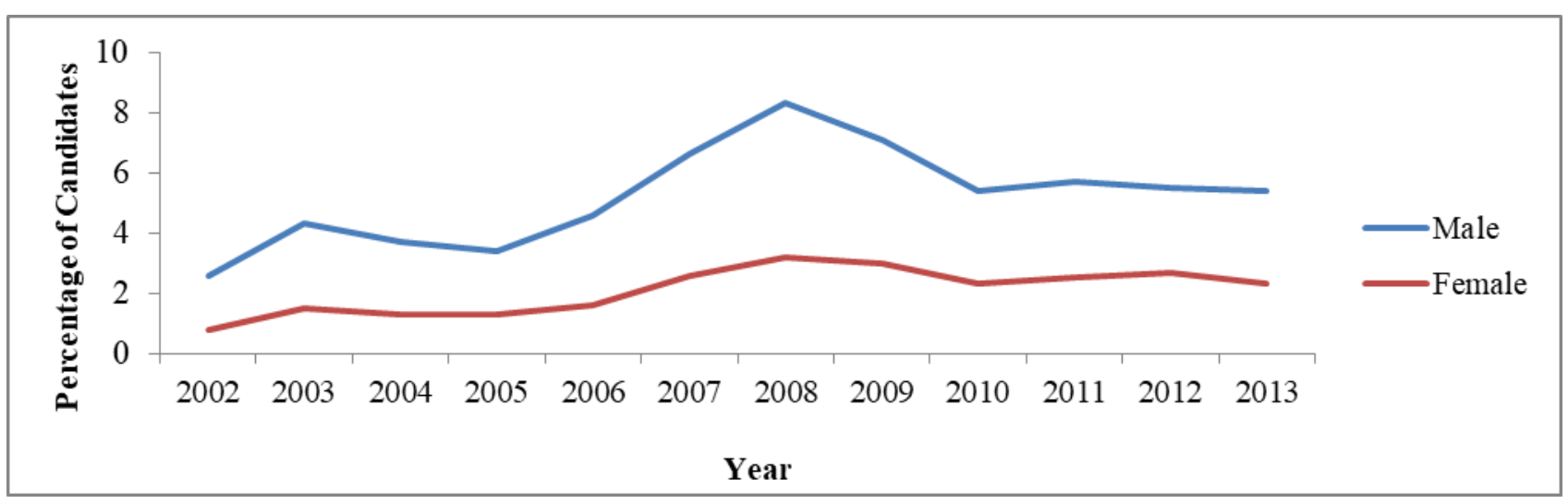

The Figure III. Gender- wise Success Rate* of Candidates in CSE (P)

* Success rate is the number of candidates qualified as a percentage of those who take the preliminary exam.

The average success rate of male candidates for the period of 2002 to 2013 is 5.2 percent while the success rate of female candidates is 1.9 percent for the corresponding period. In other words, male success rate is three times more than that of female. Obvious reasons for females such dismal and poor performance is rooted in patriarchy, stereotypes and attitudes towards female and lack of access to resources among others. 


\subsection{Women's Performance in Civil Service (Main) Examination}

The figure IV below portrays that the performance of female candidates in CSE(M) is better than that of male candidates.

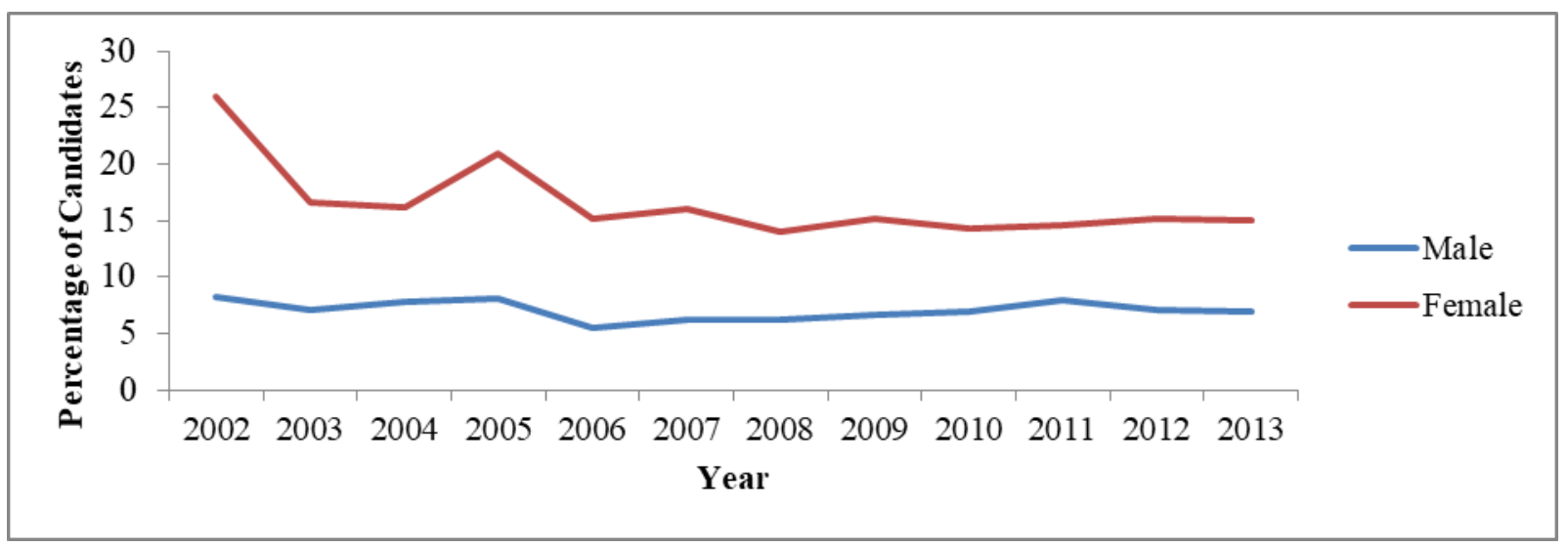

The Figure IV: Gender- wise Success Rate* of Candidates in CSE (M)

* Success rate is the number of candidates recommended as a percentage of those who take the main exam.

The data present a paradoxical picture when the data of women's performance in $\operatorname{CSE}(\mathrm{P})$ is juxtaposed with their performance in $\operatorname{CSE}(\mathrm{M})$. Because on the one hand females' performance in $\operatorname{CSE}(\mathrm{P})$ is extremely poor in comparison to male. But on the other hand, female candidates totally outperformed male candidates in $\operatorname{CSE}(\mathrm{M})$ consistently. This enigma can be unknotted by discerning patriarchal attitudes and stereotypes towards women. Once female candidates sail smoothly through the preliminary examination, their parents, relatives, neighbours and so on put their stamp of approval regarding women's merit and potentialities. Consequently, these women somehow are treated at par with their male counterpart for the rest of race for civil service. Now parents are ready to put their bet on their daughters (who qualified CSE-P) so that their worth can be enhanced in prospective marriage market. In other words, they have access to resources and high mobility to enter in public spaces (coaching institutes, odd hour outing for studies etc) and so on.

\subsection{Age-Wise Success Ratio of Female Candidates in Civil Service Examination (Main)}

The data in figure $\mathrm{V}$ reveals that on average female candidates from age group (21-25) has the highest success ratio in the civil services (main) examination. Further, females candidates from age group ( $30 \&$ above) constitute the least number who make it to the final selection in the civil services. The average of successful female candidates from age group (21-25) is 28 percent for the period of 2002 to 2013 while the average of age group (30 \& above) is 8.7 percent for the corresponding period.. In other words, it can be argued that with an increase in age of females candidates, chances of their success start decline. And once they have touched the mark of 30 years, dimmer it be for them to make it to the list of successful candidates. 


\section{Macrothink}

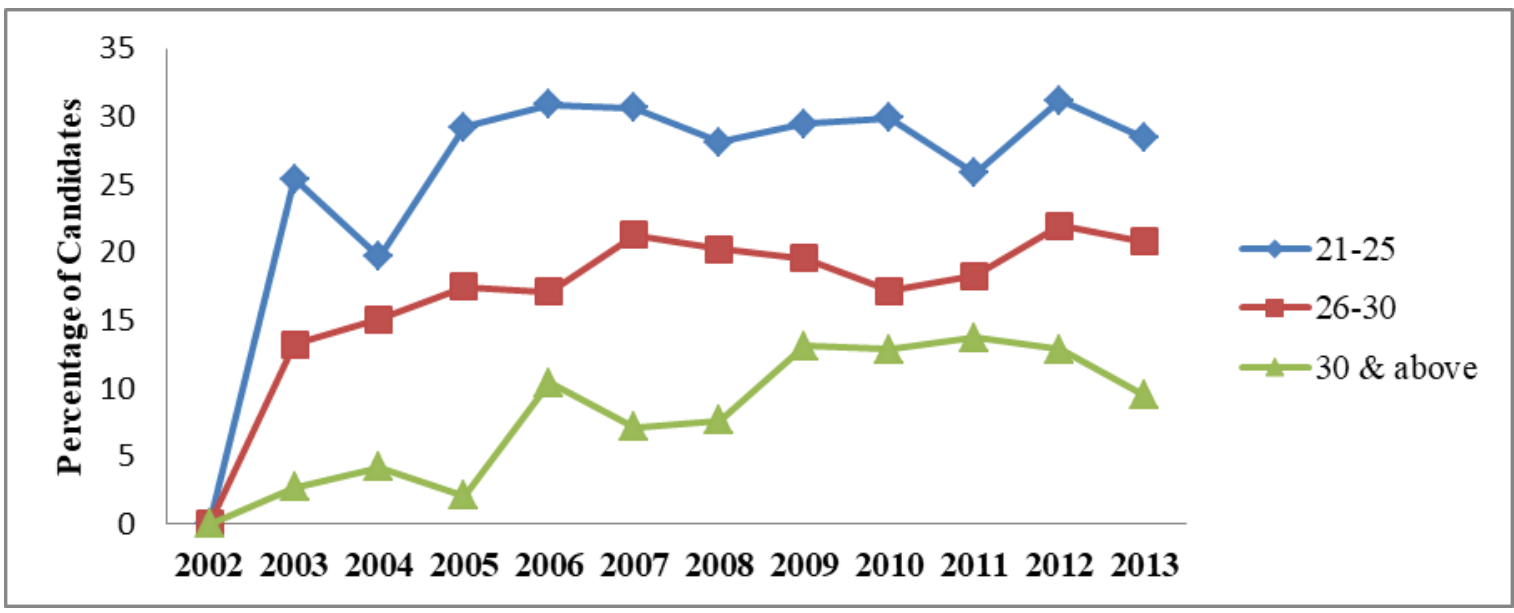

Figure V. Age-wise successful female candidates in CSE(M)

The most obvious explanation of this variation is social roles and expectation in the society, that is, marriage and family. According to the report Women and Men in India 2016 released by the central government's Ministry of Statistics and Programme Implementation, the mean age of women at the time of marriage in 21 major states was 22 years and 3 months in 2014. While the mean age of marriage for men is substantial higher i.e. 28 years that means 6 years benefit for men. As the country witnessed economic development, education and literacy levels improved, and mindsets changed. Actually the dividends of development are dispersed unevenly across the gender - men and women. In nutshell, man as a class is major beneficiary of growth and advancement. And women are bearing the burden of patriarchy and capitalism (Walbly, 1990).

To some extent similar findings and conclusions have been offered by the survey conducted by the Centre for the Study of Developing Societies in partnership with Konard Adenauer Stiftung (CSDS-KAS, 2017). The data shown in the table IV given below, the study titled Attitudes, Anxieties and Aspirations of India's Youth: Changing patterns, sought to answer key questions about how India's youth thought and lived especially social and cultural views on attitudes towards women. The respondents were aged 15-34 and interviews were conducted across the country. Socially and culturally, Indian youth are yet to be liberated from the clutches of conservative moorings. A majority 51 percent agreed (strongly/somewhat) that wives should always listen to their husbands. Only two in very five or 40 disagreed with paterfamilias paradigm of the society. Moreover, two-fifths of the youth (41 percent) are, suffering from 'Mill syndrome' (i.e. women bear and rear children), concurred that it is not right for women to do a job after marriage. Mill assumed that marriage is a free contract between real equals. He also assumed that women's choice of family over career was entirely voluntary and that such a choice involved women consenting to put their other interests in life on back burner until their children were adult. 
Table IV. Social and Cultural views - Attitude towards Women

\begin{tabular}{llc}
\hline SN & \multicolumn{1}{c}{ Statement } & $\begin{array}{c}\text { 'Agree } \\
\text { and 'Somewhat agree' } \\
(\mathbf{\%})\end{array}$ \\
\hline $\mathbf{1}$ & Women should not work after marriage & $\mathbf{4 1}$ \\
$\mathbf{2}$ & Overall, men are better leaders & $\mathbf{4 3}$ \\
$\mathbf{3}$ & Higher education is more important for boys & $\mathbf{3 7}$ \\
$\mathbf{4}$ & Wives should always listen to husbands & $\mathbf{5 1}$ \\
\hline
\end{tabular}

(Source: The study was conducted among 6122 individuals ages between 15 to 34 by Centre for Study for Developing Society (CSDS) in partnership with KAS in 19 Indian states during April and May 2016)

\subsection{Issue of Drop-out in the Civil Services Examination (Preliminary)}

It can be seen from table III that in 2013 out of 7,55,103 lakh candidates who had applied for the $\operatorname{CSE}(\mathrm{P})$, only $2,18,355$ lakh or 29 percent are female candidates. Further, merely 76,458 or 35 percent of the total female candidates had appeared for the exam. In other words, there was a drop-out rated of 65 percent among female. Moreover, the data reveals that female's drop-out rate is significantly higher among female than the male as well as overall drop-out rate among total candidates.

Further analysis of the decennium figures divulges that the drop-out rate of female is increasing especially from last 3-4 years. Whereas the drop-out rate of male remained more or less stable over the same period. The data uncovers that around two-third of female candidates disappears from the arena in between the process of application to taking the exam.

Table III. Drop-out rate of Male and Female candidates at CSE (P)

\begin{tabular}{c|c|c|c}
\hline Year & Overall Percent & Male Percent & Female Percent \\
\hline 2002 & 47.8 & 47.3 & 50.0 \\
\hline 2003 & 49.2 & 48.8 & 50.7 \\
\hline 2004 & 50.0 & 49.3 & 52.6 \\
\hline 2005 & 49.2 & 49.7 & 51.3 \\
\hline 2006 & 49.0 & 48.2 & 51.4 \\
\hline 2007 & 51.6 & 51.1 & 53.3 \\
\hline 2008 & 48.7 & 47.9 & 61.3 \\
\hline 2009 & 52.8 & 52.1 & 55.0 \\
\hline 2010 & 50.9 & 49.5 & 54.9 \\
\hline 2011 & 51.3 & 49.4 & 56.3 \\
\hline 2012 & 50.7 & 48.4 & 57.0 \\
\hline 2013 & 57.9 & 55.0 & 65.0 \\
\hline
\end{tabular}


(Source: Union Public Service Commission Annual Report from 2002 to 2013)

\section{Factors affecting Gender Equity in the Civil Services of India}

These are the many overt and covert 'factors that impede women's visibility in public spaces in general and civil services in particular. These are discussed in the following text:

\subsection{Personal Factors}

Due to differently embedded in social, familial hierarchy personal factors meddle women's behaviour, perceptions, attitude and so on especially in relation to professional life vis-a-vis private life.

- Institutionalisation and prioritisation of domestic role such as childcare, family and elders' responsibilities over career aspirations.

- Lack of education is the biggest hurdle for women's visibility in public spaces. Gender discrimination exists from primary education level and there is a gap in male-female literacy.

\subsection{Structural}

These are the many overt and covert 'glass-ceiling' factors that impede women's career paths.

- These include: male managerial styles, discourse and language that 'shut' women out;

- informal organizational cultures also referred to as the 'old boys club'; women's reluctance to self-promote their achievements and capabilities making them institutionally invisible;

- There are women well-qualified for academic positions who nevertheless fail to be selected. Customarily both politicians and bureaucrats are predispose to patriarch ideology - 'a man is preferred because he is a man'.

- Discriminatory appointment and promotion practices constitute barriers in institutions without equal opportunity policies. In other words, a large part of the problem is the entrenched notion that men were more 'natural' leaders than women - something exacerbated by the increasing use of generally male-led and male-dominated search committee/s for appointment

- Lack of access to resources and property rights

\subsection{Socio-Cultural Factors}

Deeply entrenched gender roles and negative gender stereotyping have immensely limited women's participation in public domain.

- Traditional cultural attitudes and values are serious constraints to achieving gender equality. Strong and different values on gender-roles create barriers, discriminate against women and impede the achievement of equality between men and women in Indian society 
- The dual burden of domestic and professional obligations and economic resource constraints restrict opportunities for women to participate in political and public life.

- Hierarchical social structures and culture of public patriarchy create an environment that impedes women's ability to be equal partners in public decision-making. Stereotypes continue to consider women as subordinates who cannot participate in politics and hold senior decision-making positions.

- Generally women are bereft of vital resources (economic, political and cultural) that are pre-requisite while negotiating for their entry in public institutions.

\subsection{Institutional Factors}

Despite a robust gender equality perspective reflected in national gender equality policy initiatives and legal frameworks, challenges remain.

- Discrimination impacts the ability of women to be promoted. Gender specific gaps in national laws, including the absence of a comprehensive definition of 'gender-based discrimination' contribute to the challenge of addressing discrimination against women, including in appointed and elected positions.

- Decision-making processes and structures form additional barriers for women to participate in public and political life. Women are concentrated in sectors traditionally associated with women and at the lower levels of government. Opportunities for women to participate in decision-making processes in sectors such as economics, industry and energy, mines, urban management and transport are further constrained.

\section{Conclusion}

Nevertheless women on the top of UPSC results but fail to break male stranglehold in overall civil service. Since 2010 women are bagging topper slot in coveted and prestigious civil services except 2013, yet gender parity in Indian higher civil service is elusive and still a distant dream. Women are not adequately represented in, so called 'backbone of administration', Indian bureaucracy. There is only one femocrat out of every five bureaucrats in India. In fact, a look at past three year figures show that there is a slight decline in successful women candidates in civil service examination. Such institutionalization of gender roles, domesticity, stereotypes, lack of education, access to resources and gender discrimination among others do not prepare and facilitate girls for full and equal participation in the civil service and thereby limits their career horizons. Thus, women in India have to face systemic, social, familial and cultural obstacles to pursue their career in civil service.

Seeing that there are institutionalization of practices, patterns and beliefs, corollary, women are often assumed to be less available for leadership positions by those who hire. Additionally, many women make career decisions around issues of family, while many men make family decisions around issues of career. The impact of gender inequality on governance is as debilitating as it is widespread. Complicated by other intersecting hierarchies, such as class, caste, ethnicity and religion, the differences ascribed to women and men on the basis of sex are recreated, maintained and manipulated in contests for state power and resource allocation. 


\section{I Macrothink}

Journal of Public Administration and Governance

ISSN 2161-7104

2019, Vol. 9, No. 3

Women's presence within the executive branch is also politically important. The chief executive and the cabinet set the policy agenda of a nation and determine the content of many policies. Moreover, policy implementation and administration of policies for the advancement of women is the domain of executive. The global literature suggests that women and men in public institutions are largely placed differently, with differential access to leadership, and hence transport dissimilar influences, meanings, discourses and practices. Gender in governance is about more than focussing on women's under-representation. Thus the fate of further advances in the status of women, especially in managerial positions in public life, to a large extent depends on broader structural, institutional and cultural changes.

\section{References}

Bureau of Police Research and Development. (2015). Annual Report 2015-16.

Cabinet Office, UK (2008). Senior Civil Servants' Survey 2006. http://www.civilservice.gov.uk/about/facts/statistics

CSDS-KAS Report. (2017). Attitudes, Anxieties and Aspirations of India's Youth: Changing patterns. https://www.lokniti.org/pol-pdf/KeyfindingsfromtheYouthStudy.pdf

Dwivedi, P. O., Jain, D. B., \& Dua, D. B. (1989). Imperial legacy, bureaucracy, and administrative changes: India 1947-1987. Public Administration and Development, 9, 253-69

Garrett, S. (1992). Gender. London : Routledge.

Govt. of India. (1997). A Report of the Fifth Central Pay Commission (Vol. II).

Govt. of India. (2010). Civil Services Survey - A Report. https;//darpg.gov.in/sites/default/files/Civil_Services_Survey_2010

Maheshwari, S. R. (2005). Public Administration in India: The Higher Civil Service. New Delhi: OUP.

Ministry of Education and Social Welfare (1974). Towards Equality: The Report of the Committee on the Status of Women in India. New Delhi. Government of India

Mishra, R. K. (2001). The national civil service system of India: A critical view. In J. P.

Public Service Human Resources Management Agency of Canada. (2008). Public Service Employee Survey. https://www.tbs-sct.gc.ca/pses-saff/2008/report-rapport-eng.asp

Sen, A. (1999). Development as freedom. New York: Knopf.

Swarup, H. L., \& Sinha, N. (1991). Women in public administration in India. In J. H. Bayes (ed.), Women and public administration: International perspectives. NY: The Haworth Press.

UGC (2012). Annual Report 2011-12. New Delhi

UNDP (2010), Human Development Report 2010. New York: Oxford University Press.

Union Public Service Commission (2002). Annual Report from 2002 to 2015. New Delhi. 
Walby, S. (1990). Theorising Patriarchy. Oxford: Blackwell.

World Bank (2011). World Development Report. Defining gender in the 21st century. Washington DC: World Bank.

\section{Copyright Disclaimer}

Copyright for this article is retained by the author(s), with first publication rights granted to the journal.

This is an open-access article distributed under the terms and conditions of the Creative Commons Attribution license (http://creativecommons.org/licenses/by/4.0/). 